\title{
The Endochitinase of Clonostachysrosea Expression in Bacillus amyloliquefaciens Enhances the Botrytis cinerea Resistance of Tomato
}

\author{
Yangyang Zheng ${ }^{1,+} \mathbb{C}$, Xudong Wang ${ }^{1,+}$, Siyuan Liu ${ }^{2}$, Kewei Zhang ${ }^{2}$, Zhibo Cai ${ }^{1}$, \\ Xiuling Chen ${ }^{2}$, Yao Zhang ${ }^{1}$, Jiayin Liu ${ }^{3}$ and Aoxue Wang ${ }^{1,2, *}$ \\ 1 College of Life Sciences, Northeast Agricultural University, Harbin 150030, China; \\ zhengyangyang625@163.com (Y.Z.); 13552607994@163.com (X.W.); dabaozicaizhibo@163.com (Z.C.); \\ zy13263696020@163.com (Y.Z.) \\ 2 Key Laboratory of Biology and Genetic Improvement of Horticultural Crops (Northeast Region), Ministry of \\ Agriculture/Northeast Agricultural University, Harbin 150030, China; liusiyuan6992@126.com (S.L.); \\ zhangkewei225@163.com (K.Z.); xiuling.chen@ymail.com (X.C.) \\ 3 College of Sciences, Northeast Agricultural University, Harbin 150030, China; 13040216@163.com \\ * Correspondence: axwang@neau.edu.cn; Tel.: +86-133-0465-0836; Fax: +86-045-155-191671 \\ + These authors contributed equally to this work.
}

Received: 16 June 2018; Accepted: 24 July 2018; Published: 30 July 2018

\begin{abstract}
To investigate whether the ech 42 gene in Clonostachysrosea can improve the biocontrol efficacy of Bacillus amyloliquefaciens and its molecular mechanism. Compared to the wild type, the B. amyloliquefaciens transformed with the ech42 gene exhibited higher chitinase activity. The B. amyloliquefaciens-ech42 also showed significantly higher biocontrol efficiency compared to Botrytiscinerea when tomato plants were pre-treated with B. amyloliquefaciens-ech42. No significant difference in biocontrol efficiency was observed between the wild type and B.amyloliquefaciens-ech42 when tomato plants were first infected by Botrytiscinerea. In addition, the activity of the defense-related enzyme polyphenol oxidase, but not superoxide dismutase, was significantly higher in B. amyloliquefaciens-ech42 than in the wild type. The ech42 enhances the biocontrol efficiency of B.amyloliquefaciens by increasing the capacity of preventative/curative effects in plants, rather than by killing the pathogens.
\end{abstract}

Keywords: Bacillus amyloliquefaciens; chitinase; defense enzymes; biological control

\section{Introduction}

Biological control (biocontrol) of phytopathogens provides an attractive alternative means of managing plant diseases [1]. It is highly efficient and causes no harm to the environment or to human health. Clonostachysrosea is a fungus commonly found in the environment and non-pathogenic to plants. It is a plant probiotic, which belongs to the family Moniliaceae [2]. C. rosea is a common soil fungus, with a wide range of hosts [3], able to withstand adverse environments [4]. The fungus C.rosea has been successfully tested as a biocontrol species against many plant pathogenic fungi, and has shown great potential in controlling plant diseases and promoting crop growth [5-9]. C. rosea inhibits the growth of pathogenic fungi mainly by producing extracellular lytic enzymes, especially chitinase, which can degrade chitin, the main component of fungal cell walls [10,11]. Other studies have shown that chitinase mayenhance the inhibition of many plant pathogens [12-15].

The antifungal effect of chitinase was first reported by Horikoshi and Iida, who found that Bacillus circulans exerted lytic activity against Aspergillusoryzae, and that the addition of chitinase increased the lytic activity [16,17]. Over-expression of the chitinase gene (chit36 or chit42 of Trichodermaharzianum and cht42 of T. virens) enhanced the inhibition to Botrytiscinerea [12-15]. 
Another well-studied biocontrol agent is Bacillus amyloliquefaciens, which inhibits plant pathogens by producing low molecular weight antibiotics and other active substances such as B.amyloliquefaciens antibiotic production [18]. B. amyloliquefaciens can also promote plant growth [19]. Purification of chitinases from B. amyloliquefaciens has also been reported $[14,20]$, and these chitinases displayed antifungal activities.

In this study, in an effort to further enhance the antifungal activity of B. amyloliquefaciens, the endochitinase gene of $C$. rosea (encoded by ech42), was transformed into B. amyloliquefaciens. The biocontrol effects of $B$. amyloliquefaciens-ech42 in vitro against Botrytiscinerea were investigated and our results provided evidence of substantially improved inhibitory effects on Botrytiscinerea.

\section{Results}

\subsection{Construction of $\mathrm{pHT} 43-\mathrm{ech} 42$}

Digestion of the plasmid pHT43-ech42 by Xba I and Sma I showed that the pHT43 vector and the ech 42 gene were about 7000 and $1300 \mathrm{bp}$ respectively, which matched the expected sizes. The results of single and double digestion showed that the recombination vectors of pTH43-ech42 were constructed successfully (Figure S1).

\subsection{Transformation of ech 42 Gene to B. amyloliquefaciens}

For electroporation transformation, different voltages were used to test the transformation efficiency. The highest number of transformants was obtained at $15 \mathrm{kv} / \mathrm{cm}$ and no transformants were obtained at $20 \mathrm{kv} / \mathrm{cm}$ or $21 \mathrm{kv} / \mathrm{cm}$, probably due to the increase in cell death.

\subsection{Detection the Growth Curves of B. amyloliquefaciens and Recombinant B. amyloliquefaciens Strains}

The growth rate of recombinant strain (B. amyloliquefaciens-ech42) was slower than the wild type (B. amyloliquefaciens). The difference in growth rates gradually increased after $14 \mathrm{~h}$ culture and reached a maximum after $24 \mathrm{~h}$ (Figure S2).

\subsection{Detection of Recombinant ech42 Protein by SDS-PAGE}

SDS-PAGE showed a $42 \mathrm{kDa}$ protein band in B. amyloliquefaciens-ech42 in the presence of IPTG. However, no similar band was observed in B. amyloliquefaciens-ech42 in the absence of IPTG or in B. amyloliquefaciens induced with IPTG (Figure 1a). The $42 \mathrm{kDa}$ band was similar to the molecular mass of ech42, indicating that the ech42 was successfully expressed in the B. amyloliquefaciens-ech 42 strain.

\subsection{Chitinase Activity of B. amyloliquefaciens and B. amyloliquefaciens-ech42}

A chitinase activity assay showed that the B. amyloliquefaciens-ech42 displayed significantly higher chitinase activity than the wild type strain. The activity of B. amyloliquefaciens-ech 42 was highest at the $8 \mathrm{~h}$ incubation $(0.156 \pm 0.012 \mathrm{U} / \mathrm{mL})$, which was 1.54 times higher than that of the wild type strain $(0.101 \pm 0.014 \mathrm{U} / \mathrm{mL})$ (Figure $1 \mathrm{~b})$. The activity of the wild type was highest at $12 \mathrm{~h}(0.133 \pm 0.007 \mathrm{U} / \mathrm{mL})$, 1.13 lower than the activity of B. amyloliquefaciens-ech $42(0.15 \pm 0.003 \mathrm{U} / \mathrm{mL})$ at the same time point.

\subsection{Biocontrol Efficiency of B. amyloliquefaciens-ech42 vs. Botrytiscinerea in Greenhouse}

The biocontrol efficiency of B. amyloliquefaciens-ech42 against Botrytiscinerea was further tested using tomato plants in a greenhouse setting. In the prevention experiment (Figure 2a,b), the B. amyloliquefaciens-ech42 exhibited significantly higher biocontrol efficiency, compared to the wild type B. amyloliquefaciens, at both day 15 and day 20. However, in the treatment experiment, no significant differences in biocontrol efficiency were observed between the wild type and B. amyloliquefaciens-ech42 (Figure 2c,d). These results suggest that the increased chitinase activity in B. amyloliquefaciens works more efficiently in plant pathogen prevention than in pathogen treatment. 
a

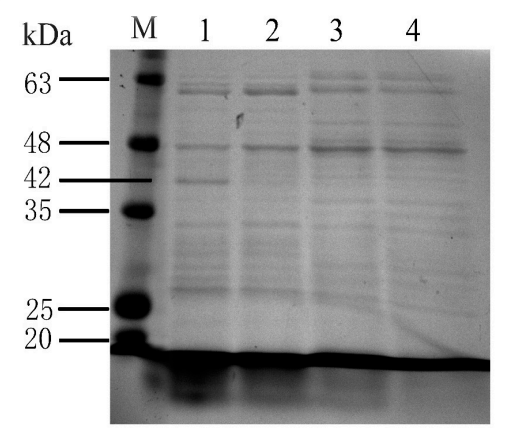

b

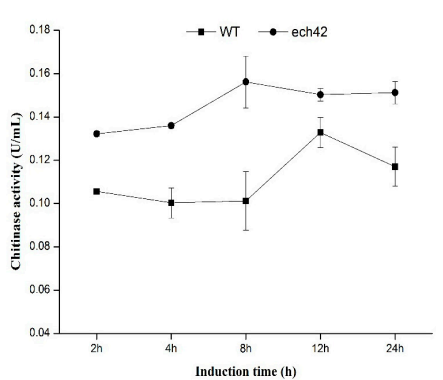

Figure 1. ech42 protein expression analysis of B. amyloliquefaciens and B. amyloliquefaciens-ech42. (a) SDS-PAGE showing the ech42 protein from B. amyloliquefaciens-ech42. M. Protein Marker; (1) B. amyloliquefaciens-ech42 induced by IPTG; (2) B. amyloliquefaciens-ech42 without IPTG induction; (3) B. amyloliquefaciens induced by IPTG; (4) B. amyloliquefaciens without IPTG induction; (b) Comparison of chitinase activities of B. amyloliquefaciens and B. amyloliquefaciens-ech42.

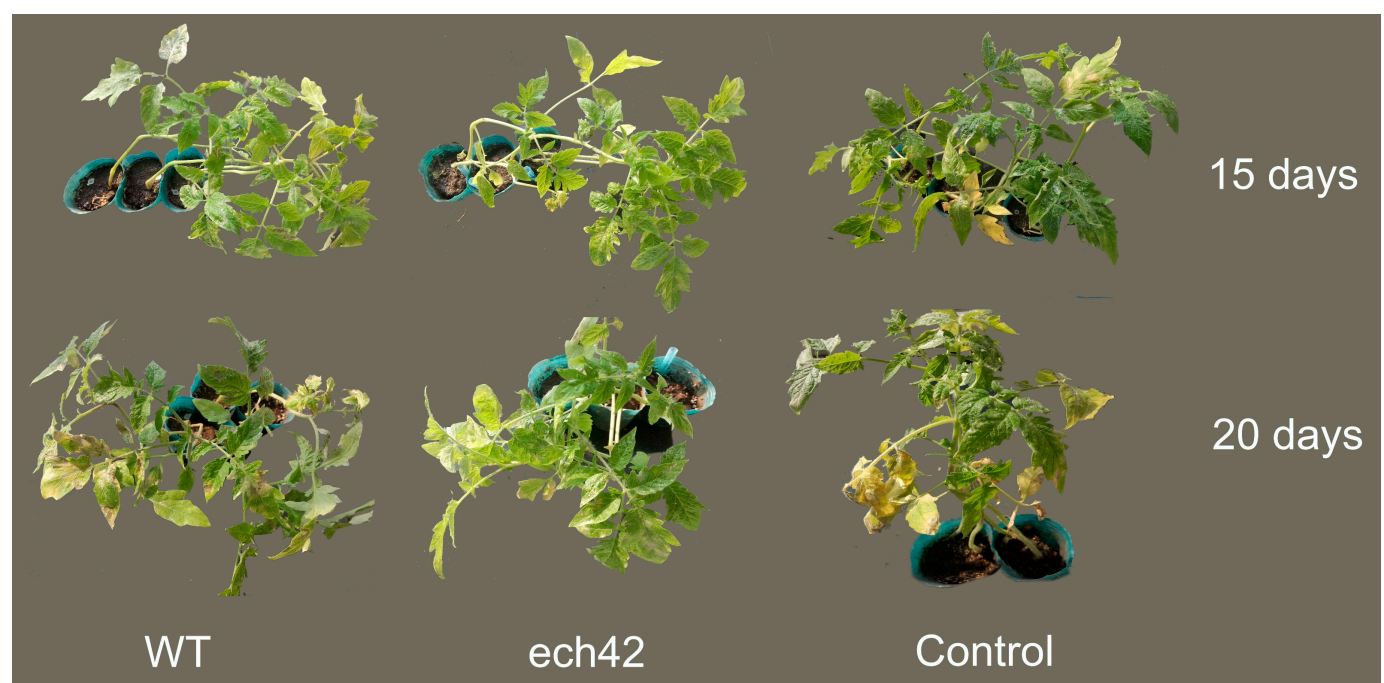

(a)

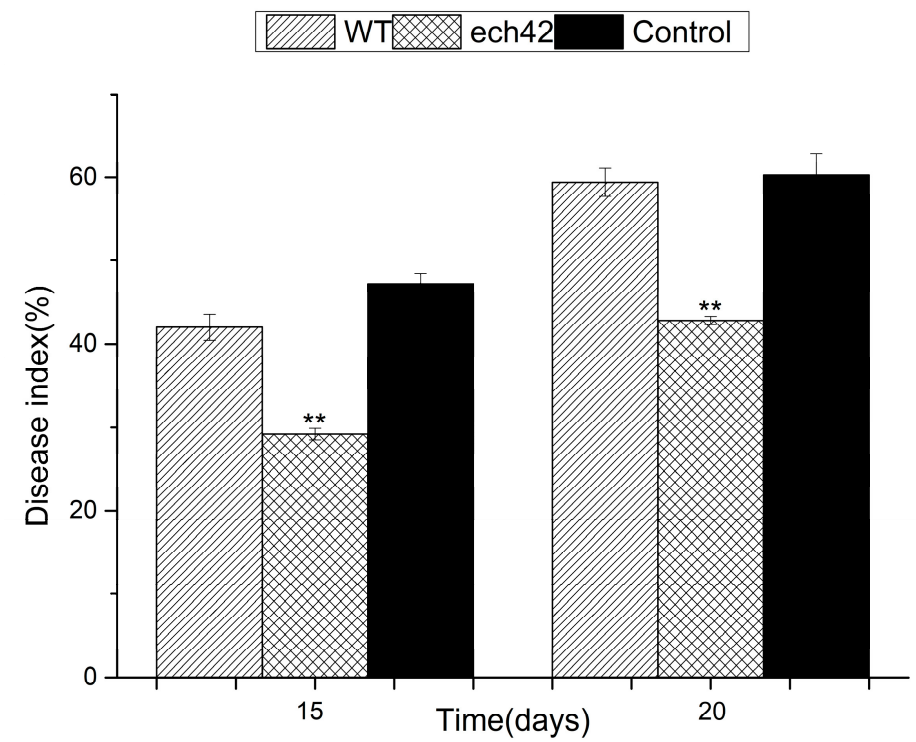

(b)

Figure 2. Cont. 


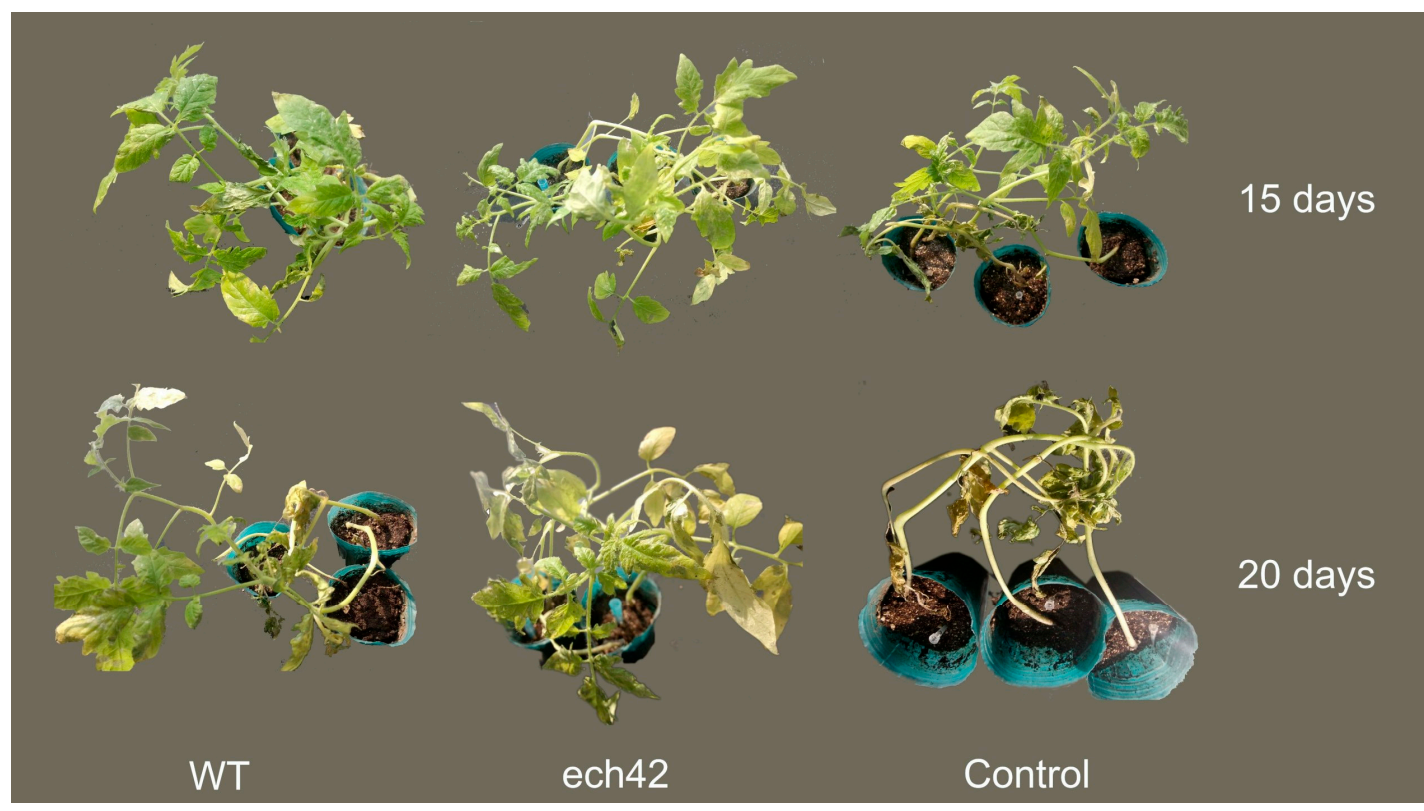

(c)

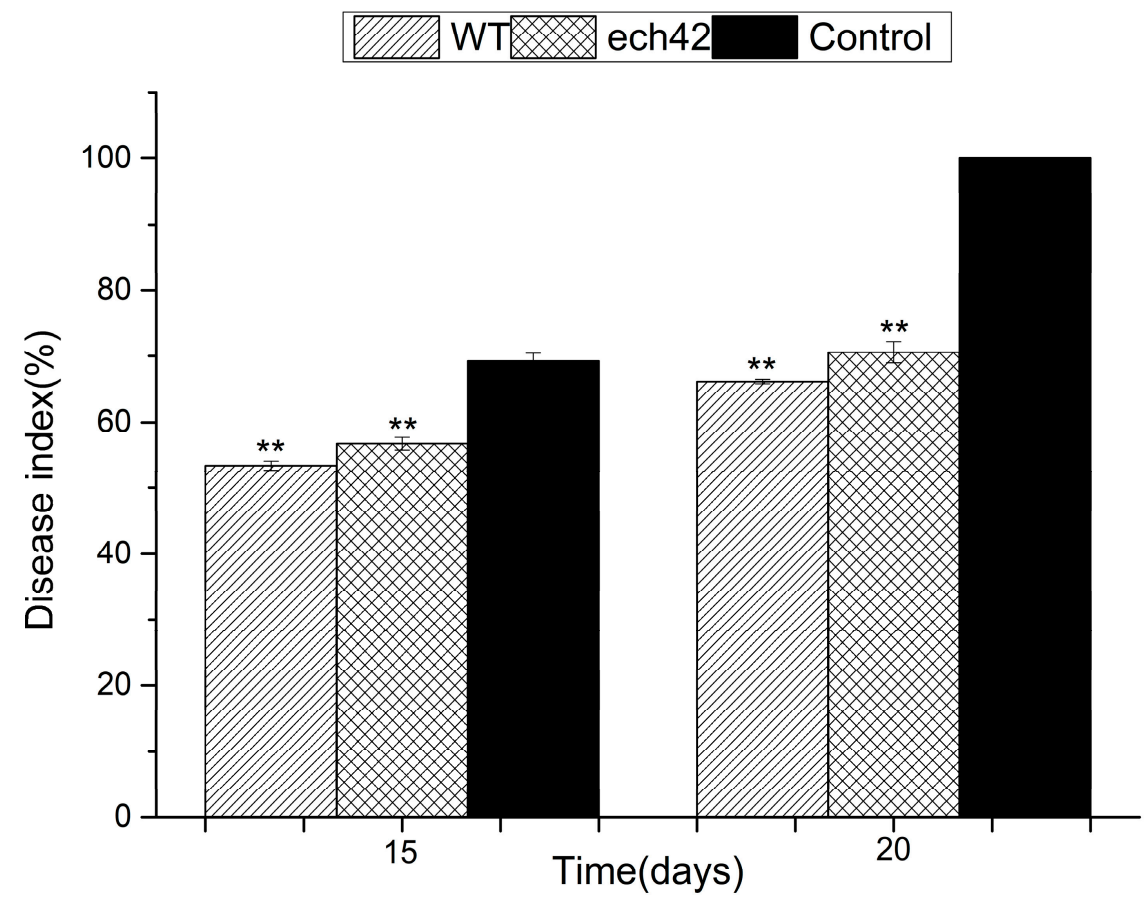

(d)

Figure 2. The biocontrol efficiency of B. amyloliquefaciens-ech42 against Botrytiscinerea on tomato plants. The prevention experiment $(\mathbf{a}, \mathbf{b})$ : (a) Representative images of tomato plants treated with wild type B. amyloliquefaciens (WT), B. amyloliquefaciens-ech42 (ech42) or non-treated (control); (b) disease indexs in the prevention experiment at 15 and 20 days. The treatment experiment (c,d): (c) Representative images of tomato plants treated with wild type B. amyloliquefaciens (WT), B. amyloliquefaciens-ech42 (ech42) or non-treated (control); (d) disease index in the treatment experiment at 15 and 20 days. Differences between the treatment and control were analyzed using ANOVA and significant results are indicated by ${ }^{* *}(p<0.01)$. 


\subsection{Changes in Defense-Related Enzyme Activity}

During the prevention and treatment experiments, fresh leaves were collected from all treatment groups to test the enzyme activities of both PPO and SOD. In the prevention experiments, the activities of PPO with B. amyloliquefaciens-ech42 were significantly higher than those of B. amyloliquefaciens or the control (days 3-5). Compared to B. amyloliquefaciens or the control, B. amyloliquefaciens-ech42 displayed higher PPO activity in the treatment experiment at day 7 (Figure 3a,c). The SOD activities of both the wild type and B. amyloliquefaciens-ech42 were significantly higher than those of the control group, but no significant differences were observed between the wild type and B. amyloliquefaciens-ech42 (Figure 3b,d).

a

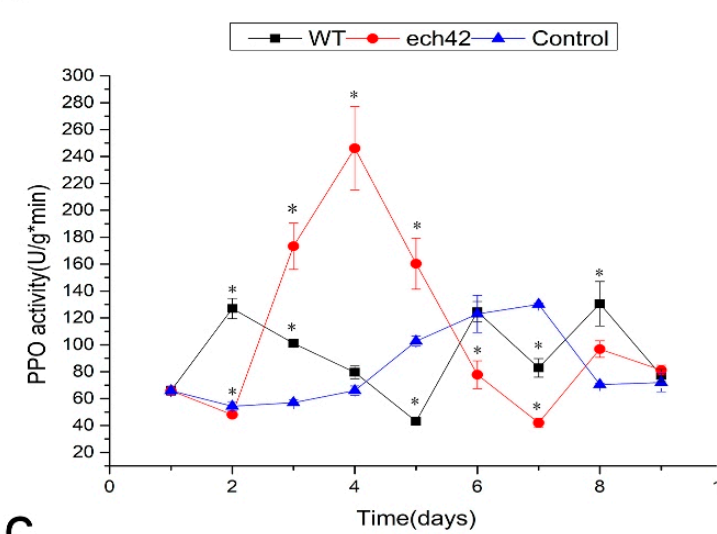

C

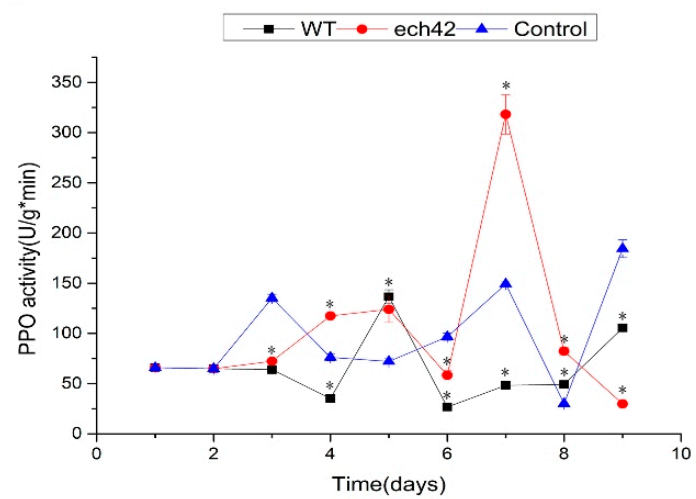

b
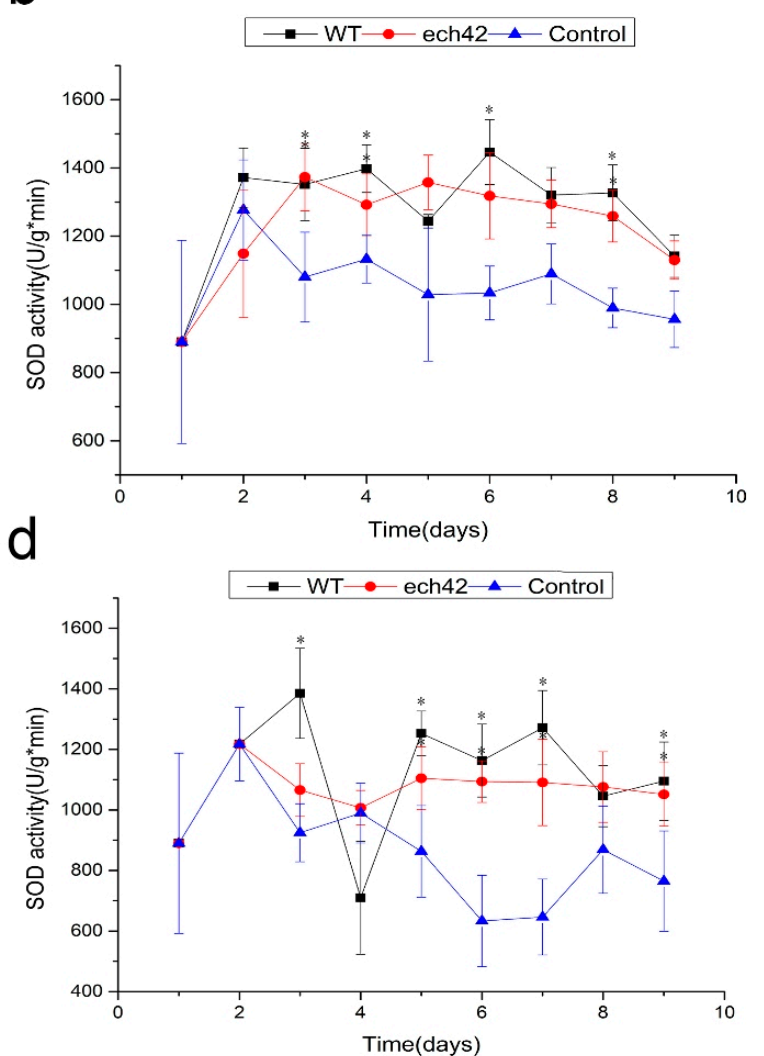

Figure 3. Changes of PPO $(\mathbf{a}, \mathbf{c})$ and SOD $(\mathbf{b}, \mathbf{d})$ activities during prevention $(\mathbf{a}, \mathbf{b})$ and treatment (c,d) experiments against Botrytiscinerea on tomato plants. WT: B. amyloliquefaciens; ech42: B. amyloliquefaciens-ech42; control: not treated with either WT or ech42. "**": indicates statistically significant results.

\section{Discussion}

In this study, we transformed the endochitinase ech 42 gene isolated from C. rosea into the biocontrol bacterium B. amyloliquefaciens. We then compared the biocontrol efficiency between the wild type and the B. amyloliquefaciens over expressing the chitinase. Consistent with previous studies, we showed that the increased chitinase in B. amyloliquefaciens-ech42 was effective for inhibiting the growth of Botrytiscinerea. We also showed that B. amyloliquefaciens-ech42 was more efficient in plant pathogen prevention than in pathogen treatment.

The transformation efficiency of plasmid was affected by several factors, with the main factor being applied voltages. In this study, the highest number of pHT43-ech42 transformants were obtained with $15 \mathrm{kv} / \mathrm{cm}$, and no transformants were obtained at $20 \mathrm{kv} / \mathrm{cm}$ or $21 \mathrm{kv} / \mathrm{cm}$. This is 
consistent with a previous study, which showed the transformation frequency was $12 \mathrm{kV} / \mathrm{cm}$, and that subsequently, transformation frequency reduced with increased voltage, probably due to the increase in cell death [21].

In this study, we found that the growth rate of B. amyloliquefaciens-ech42 was lower than that of the wild type. In contrast, a previous study showed that the growth rate of a recombinant strain was higher than that of a wild type of Streptomyces sp [17]. The authors speculated that over expression of chitinase could degrade chitin (the solocarbon source) into glucose, further supporting cell growth [15].

To further understand the molecular mechanism of the ech42 enhanced biocontrol effect, we investigated the activities of two defense-related enzymes, PPO and SOD. PPO is an oxidase and catalyzes the oxidation of monophenols and o-diphenols to o-diquinones, which can ultimately produce brown or red pigments that cause fruit browning. PPO also plays important roles in disease resistance. It has been shown that over expression of PPO increased resistance to the bacterial pathogen, Pseudomonas syringae [22]. SOD acts as an antioxidant that catalyzes the dismutation of reactive oxygen species, which cause oxidative stress and damage to cells [1]. In this study, we found that the PPO and SOD activities of B. amyloliquefaciens-ech42 were significantly higher than those of the wild type, when tomato plants were treated first with B. amyloliquefaciens-ech42 (prevention experiment). However, when the plants were treated first with the plant pathogen Botrytiscinerea, the PPO and SOD activities were not significantly higher. Our results strongly suggest that chitinase of B. amyloliquefaciens-ech 42 enhances the biocontrol efficiency by increasing the prevention capacity of plants, rather than by killing the pathogens. As a result, a good strategy for effective biocontrol is to apply the biocontrol agents as early as possible to boost the "immune system" of plants.

One limitation of our study is that our results do not confirm whether the enhanced biocontrol efficiency of the recombinant B. amyloliquefaciens (B. amyloliquefaciens-ech42) is caused primarily by the increased level of chitnase. It is possible that the insertion of ech42 may cause other changes to B. amyloliquefaciens. Studies using purified chitinase are needed to further understand the biocontrol mechanism of B. amyloliquefaciens.

In conclusion, our study demonstrated that insertion of the C. rosea endochitinase gene ech42 into B. amyloliquefaciens significantly enhanced the chitinase activity and its biocontrol efficiency. Our results suggest that the increased biocontrol efficiency may be caused by the increased capacity of preventative/curative effects in plants, rather than by killing the pathogens.

\section{Materials and Methods}

\subsection{Strains and Culture Conditions}

Bacterial and fungal strains used in this study are listed in Table S2, and the bacterial strains B. amyloliquefaciens were isolated from the fruits of tomato plants. B. amyloliquefaciens and C. rosea were cultured in Luria broth (LB) medium ( $1 \%$ tryptone, $1 \% \mathrm{NaCl}$ and $0.5 \%$ yeast extract) at $37^{\circ} \mathrm{C}$. Fungi were grown on a potato dextrose agar (PDA) plate (20\% potatoes (sliced, washed, unpeeled), $2 \%$ dextrose and $2 \%$ agar).

\subsection{Construction of ech42 Plasmid}

C. rosea was cultured in a PDA plate. RNA was extracted and reverse transcribed into cDNA, which was used as the DNA template. The primers for the C. rosea ech 42 gene were designed based on the sequence from the GenBank: DQ523687 (Table S1). The ech42 gene was amplified by a polymerase chain reaction (PCR). The PCR mixture included: $1 \mu \mathrm{L}$ of forward primer $(10 \mu \mathrm{M}), 1 \mu \mathrm{L}$ of reverse primer, $5 \mu \mathrm{L}$ of $10 \times$ EasyTaq Buffer (TransGen Biotech, Beijing, China), $0.5 \mu \mathrm{L}$ of EasyTaq DNA Polymerase (TransGen Biotech), $4 \mu \mathrm{L}$ of $2.5 \mathrm{mM}$ dNTPs, $1 \mu \mathrm{L}$ of cDNA template and $37.5 \mu \mathrm{L}$ of distilled water. The PCR conditions consisted of initial denaturation at $94{ }^{\circ} \mathrm{C}$ for $5 \mathrm{~min}$, followed by 35 cycles of denaturation at $94{ }^{\circ} \mathrm{C}$ for $30 \mathrm{~s}$, annealing at $68^{\circ} \mathrm{C}$ for $30 \mathrm{~s}$, extension at $72{ }^{\circ} \mathrm{C}$ for $1 \mathrm{~min}$, and final extension at $72{ }^{\circ} \mathrm{C}$ for $5 \mathrm{~min}$. The PCR products corresponding to the expected molecular size were 
extracted from the gels and purified using a StarPrep Gel Extraction Kit (Kangrun Biotech, Guangzhou, China), according to the manufacturer's instructions. Both the PCR products and the expression vector pHT43 (MoBiTec GmbH, Oberhausen, Germany) were digested with restriction enzymes Xba I and Sma I (ThermoFisher Scientific, Waltham, MA, USA), then linked with T4 DNA ligase (Thermo Fisher) at $22{ }^{\circ} \mathrm{C}$ overnight. Consequently, the recombinant plasmid pHT43-ech 42 was constructed and transformed into E. coli DH5 $\alpha$. The plasmid DNA was isolated and verified by DNA sequencing (Huada, Shenzhen, China).

\subsection{Transformation of ech42 Gene to B. amyloliquefaciens}

B. amyloliquefaciens was cultured at $37^{\circ} \mathrm{C}$ in growth medium ( $1 \%$ peptone, $0.5 \%$ yeast extract, $1 \% \mathrm{NaCl}$ and $9.1 \%$ sorbitol) to a final optical density of 0.85 . The cell culture was cooled on ice for $10 \mathrm{~min}$ then carefully harvested by centrifugation at $5000 \times g$ and $4{ }^{\circ} \mathrm{C}$ for $5 \mathrm{~min}$. The cells were washed four times with ice-cold electroporation medium ( $9 \%$ sorbitol, $9.25 \%$ mannitol and 10\% glycerin), and suspended in the same solution. For transformation, the electro-competent cells were mixed with column-purified recombinant plasmid DNA and loaded into pre-chilled $1 \mathrm{~mm}$ gap electroporation cuvettes. After incubation for $2 \mathrm{~min}$, the cell-DNA mixtures was shocked by $12.5 \mathrm{kv} / \mathrm{cm}, 15 \mathrm{kv} / \mathrm{cm}$, $17.5 \mathrm{kv} / \mathrm{cm}, 20 \mathrm{kv} / \mathrm{cm}$ or $21 \mathrm{kv} / \mathrm{cm}$ voltage, respectively, using a GenePulserelectroporator (Bio-Rad GenePulserX cell) with the resistance set at $200 \Omega$, resulting in a time constant of $4.5-5.0 \mathrm{~ms}$. Cells were then immediately diluted into $1 \mathrm{~mL}$ recovery medium (1\% peptone, $0.5 \%$ yeast extract, $1 \% \mathrm{NaCl}$, $9 \%$ sorbitol and $7 \%$ mannitol) and incubated at $37{ }^{\circ} \mathrm{C}$ for $3 \mathrm{~h}$ to allow expression of the antibiotic resistant gene. Aliquots of the dilutions were then spread onto LB agar plates supplemented with $5 \mu \mathrm{g} / \mathrm{mL}$ chloramphenicol.

\subsection{Detection the Growth Curves of B. amyloliquefaciens and the Recombinant Strain}

The wild type B. amyloliquefaciens, and the recombinant strain (B. amyloliquefaciens-ech42), were inoculated in LB liquid medium with $5 \mu \mathrm{g} / \mathrm{mL}$ chloramphenicol. The growth rates of the two strains were tested by growing them in $100 \mathrm{~mL}$ LB liquid medium at $37^{\circ} \mathrm{C}$ on a shaker $(180 \mathrm{rpm})$. The optical density (OD) was measured every $2 \mathrm{~h}$ for $32 \mathrm{~h}$ using an RS232 PRINT spectrophotometer (Nanjing Kaidi High-Speed Analytical Company; Nanjing, China) at a wavelength of $630 \mathrm{~nm}$.

\subsection{SDS-PAGE Assay}

The molecular weight of the ech42 protein was detected by SDS-PAGE. The wild type B. amyloliquefaciens, and the recombinant strain B. amyloliquefaciens-ech42, were incubated in LB liquid medium at $37^{\circ} \mathrm{C}$ with $1 \mathrm{mM}$ of IPTG for 8 h. $0.4 \mathrm{mg} / \mathrm{mL}$ lysozyme (Coolaber, Beijing, China) was added in lysis of cells. Samples were boiled for $10 \mathrm{~min}$ with 2.5\% (w/v) SDS. Proteins were separated by electrophoresis and gels were stained with Coomassie blue. The protein molecular weight marker $(14,400)$ was used as a standard to calculate the molecular mass of target preteins.

\subsection{Determination of Chitinase Activity}

Chitinase activity was determined using the 3,5-dinitrosalicylic acid (DNS) assay. The quantity of reducing sugar was calculated based on comparison with a standard curve generated from known concentrations of $N$-acetylglucosamine $(0-1 \mathrm{mg} / \mathrm{mL}) .1 \mathrm{mM}$ of IPTG was added to the culture medium of B. amyloliquefaciens-ech42 and incubated on a rotary shaker $(180 \mathrm{r} / \mathrm{min})$ at $37^{\circ} \mathrm{C}$ for $2,4,8,12$, and $24 \mathrm{~h}$, respectively. Cells were centrifuged at $8000 \times \mathrm{g}, 25^{\circ} \mathrm{C}$ for $1 \mathrm{~min}$ and $500 \mu \mathrm{L}$ of supernatant was added to $1.0 \mathrm{~mL}$ of $1 \%$ colloidal chitin (Solarbio, Beijing, China). The mixture was incubated at $37^{\circ} \mathrm{C}$ for $1 \mathrm{~h}$, and then terminated by the addition of $1.5 \mathrm{~mL}$ DNS (Coolaber, Beijing, China). The reaction was boiled in a water bath for $10 \mathrm{~min}$ then cooled to $25^{\circ} \mathrm{C}$. Next, the sample was centrifuged at $8000 \times g$ for $5 \mathrm{~min}$ and the volume was adjusted to $10 \mathrm{~mL}$ with distilled water. The absorbance was measured using a RS232 PRINT spectrophotometer (Nanjing Kaidi High-Speed Analytical Company; Nanjing, China) at $540 \mathrm{~nm}$. The experiment was performed in triplicate. 


\subsection{Tomato Plant Growth Experiment}

To test whether the B. amyloliquefaciens-ech42 strain has an enhanced effect against plant pathogens, Botrytiscinerea, which causes gray mold disease, was used in a greenhouse setting with tomato plants. Tomato plants, homozygous tomato variety 08016 (provided by the Tomato Research Institute of Northeast Agricultural University in China), were grown in a greenhouse at $25{ }^{\circ} \mathrm{C} / 22{ }^{\circ} \mathrm{C}$ (day/night) with $16 \mathrm{~h}$ light and $8 \mathrm{~h}$ dark cycles for 12 weeks. The Botrytiscinerea strain was grown at $25^{\circ} \mathrm{C}$ on a PDA plate. Botrytiscinerea spores were obtained from the surface of the 7-day old cultures and suspended in $5 \mathrm{~mL}$ of sterile distilled water containing $6.7 \mathrm{mMKH}_{2} \mathrm{PO}_{4}, 0.1 \mathrm{M}$ glucose, $0.1 \%$ Tween, and $\mathrm{pH} 5$, and then filtered through four layers of sterile cheesecloth to remove any adhering mycelia. Conidial suspensions were diluted to a concentration of $1 \times 10^{7}$ spores $\mathrm{mL}^{-1}$ with sterile water as described above. Two experiments, prevention and disease treatment, were conducted in this study. In the prevention experiment, the 8 weeks old tomato seedlings were first treated with the wild type B. amyloliquefaciens or B. amyloliquefaciens-ech42 of concentration of $10^{7} \mathrm{CFU} / \mathrm{mL}$ by spraying with a water bottle. The plants were then treated with Botrytiscinereas train after waiting for $24 \mathrm{~h}$. For the treatment experiment, 8 weeks old tomato seedlings were first treated with Botrytiscinerea for $24 \mathrm{~h}$. The seedlings were then sprayed with the wild type or the recombinant B. amyloliquefaciens. The control seedlings were sprayed with sterile water. Ninety-three fruits were divided into three groups (wild type, recombinant and control), and the SOD and PPO activities of each group were measured. The disease severity of each group was recorded [23]. after 7 days of treatment using Gong and colleagues' 9-grade scoring system based on the area of lesions on tomato leaves as follows: 0 , no symptoms; $1,<6 \% ; 3,6-10 \% ; 5,11-25 \% ; 7,26-50 \% ; 9,>50 \%$. The biocontrol efficiency of each treatment was evaluated based on the disease index which was calculated using the following formula:

Disease index $=[\Sigma($ number of infected leaves $\times$ disease grade $) /($ total number of leaves $\times$ the highest disease grade) $] \times 100$. Four replications were performed for each sample.

\subsection{Defense-Related Enzyme (PPO and SOD) Activity Assays}

PPO activity was measured according to the method used by Alamelumangai and Li [22,24], with minor modification.

To assay PPO activity, $1 \mathrm{~g}$ of fresh leaves was pulverized in $10 \mathrm{~mL}$ of buffer, containing $0.24 \mathrm{~g}$ polyvinyl polypyrrolidone (PVPP) and $0.1 \mathrm{M}$ sodium phosphate ( $\mathrm{pH} 7.0)$, in an ice bath. A total of 6 groups of leaves were collected, including leaves treated with the wild type and recombinant bacteria and control leaves (treated with water) from both the prevention and treatment experiments. The pulverized leaves were centrifuged at $10,000 \times g$ for $10 \mathrm{~min}$ at $4{ }^{\circ} \mathrm{C}$, and the supernatant was used for enzyme activity assays. A $20 \mu \mathrm{L}$ aliquot of the supernatant was mixed with $1 \mathrm{~mL}$ of a solution containing $0.4 \mathrm{~mL}$ solution $\mathrm{A}\left(7.10 \mathrm{~g} \mathrm{Na}_{2} \mathrm{HPO}_{4}, 5.25 \mathrm{~g}\right.$ Citric acid, $200 \mathrm{~mL}$ distilled water) and $0.1 \mathrm{~mL}$ solution B (2.76 g Catechol, $50 \mathrm{~mL}$ distilled water) and incubated for $10 \mathrm{~min}$ at $30{ }^{\circ} \mathrm{C}$. PPO activity was measured using a spectrophotometer at $420 \mathrm{~nm}$. One unit of PPO activity was defined as an increase in absorbance of 0.01 .

To assay the superoxide dismutase (SOD) activity, $0.5 \mathrm{~g}$ of fresh leaves [25] were placed in a pre-cooled mortar, and $1 \mathrm{~mL}$ of phosphate buffer was gradually added to the grinding process. Additional buffer was added to make the total volume to $5 \mathrm{~mL}$. The ground leaves were centrifuged at $10,000 \times g$ for $10 \mathrm{~min}$ at $4{ }^{\circ} \mathrm{C}$. A $0.05 \mathrm{~mL}$ aliquot of the supernatant was mixed with $3.25 \mathrm{~mL}$ of the reaction solution (13 mM DL-Methionine, $75 \mu \mathrm{M}$ Nitrobluetetrazolium, $10 \mu \mathrm{M}$ EDTA-Na 2 and $0.2 \mu \mathrm{M}$ Riboflavin). Phosphate buffer was used as control. SOD activity was measured using a spectrophotometer at $560 \mathrm{~nm}$. One unit of PPO activity is defined as an increase in absorbance of 0.01 .

\subsection{Statistical Analysis}

Fisher's least significant difference (LSD) test was used to compare the significance. A $p$ value $<0.05$ was considered statistically significant. 
Supplementary Materials: Supplementary materials can be found at http:/ / www.mdpi.com/1422-0067/19/8/ $2221 /$ s1.

Author Contributions: For this research articles with several authors, A.W. and Y.Z. conceived and designed the experiments; Y.Z. performed the experiments; X.W. and S.L. analyzed the data; K.Z., Z.C. and X.C. contributed analysis tools; J.L. wrote the paper.

Acknowledgments: This work was supported by Heilongjiang Provincial Science Foundation for Distinguished Young Scholars (grant number JC2015004) to Aoxue Wang, and experts of modern agricultural industry technology co-innovation system to Aoxue Wang.

Conflicts of Interest: The authors declare no conflict of interest.

\section{References}

1. Hayyan, M.; Hashim, M.A.; AlNashef, I.M. Superoxide ion: Generation and chemical implications. Chem. Rev. 2016, 116, 3029-3085. [CrossRef] [PubMed]

2. Krauss, U.; Martinez, A.E.; Ten, H.M.; Arroyo, C. Two-step liquid/solid state scaled-up production of Clonostachys rosea. Mycol. Res. 2002, 106, 1449-1454. [CrossRef]

3. Xue, A.G. Biological Control of Pathogens Causing Root Rot Complex in Field Pea Using Clonostachys rosea Strain ACM941. Phytopathology 2003, 93, 329-331. [CrossRef] [PubMed]

4. Bhatt, G.C. The soil microfungi of white cedar forests in ontario. Can. J. Bot. 2011, 48, 333-339. [CrossRef]

5. Bol, J.F.; Linthorst, H.J.M.; Cornelissen, B.J.C. Plant Pathogenesis-related proteins induced by virus infection. Annu. Rev. Phytopathol. 1990, 28, 113-138. [CrossRef]

6. Keinath, A.P.; Fravel, D.R.; Papavizas, G.C. Potential of Gliocladiumroseum for biocontrol of Verticilliumdahliae. Phytopathology 1991, 81, 239-243. [CrossRef]

7. Keyser, C.A.; Jensen, B.; Meyling, N.V. Dual effects of Metarhizium spp. and Clonostachysrosea against an insect and a seed-borne pathogen in wheat. Pest Manag. Sci. 2016, 72, 517-526. [CrossRef] [PubMed]

8. Orakc, G.E.; Yamac, M.; Amoreso, M.J.; Cuozzo, S.A. Selection of antagonistic actinomycete isolates as biocontrol agents against root-rot fungi. Fresenius Environ. Bull. 2010, 19, 417-424.

9. Schöneberg, A.; Musa, T.; Voegele, R.T.; Vogelgsang, S. The potential of antagonistic fungi for control of Fusariumgraminearum and Fusariumcrookwellense varies depending on the experimental approach. J. Appl. Microbiol. 2015, 118, 1165-1179. [CrossRef] [PubMed]

10. Manuel, D.; Robert, S.G. Antibiotics that inhibit fungal cell wall development. Annu. Rev. Microbiol. 1994, 48, 471-497.

11. Wenteish, C.; Chinshuh, C.; Sanlang, W. An Antifungal Chitinase Produced by Bacillus cereus with Shrimp and Crab Shell Powder as a Carbon Source. Curr. Microbiol. 2003, 47, 102-108.

12. Baek, J.M.; Howell, C.R.; Kenerley, C.M. The role of an extracellular chitinase from Trichoderma virens Gv29-8 in the biocontrol of Rhizoctonia solani. Curr. Genet. 1999, 35, 41-50. [CrossRef] [PubMed]

13. Limón, M.C.; Chacón, M.R.; Mejías, R.; Delgado-Jarana, J.; Rincón, A.M.; Codón, A.C.; Benítez, T. Increased antifungal and chitinase specific activities of Trichoderma harzianum CECT 2413 by addition of a cellulose binding domain. Appl. Microbiol. Biotechnol. 2004, 64, 675-685. [CrossRef] [PubMed]

14. Viterbo, A.; Haran, S.; Friesem, D.; Ramot, O.; Chet, I. Antifungal activity of a novel endochitinase gene (chit36) from Trichoderma harzianum Rifai TM. FEMS Microbiol. Lett. 2001, 200, 169-174. [PubMed]

15. Wu, Q.; Bai, L.; Liu, W.; Li, Y.; Lu, C.; Li, Y.; Fu, K.; Yu, C.; Chen, J. Construction of a Streptomyces lydicus A01 transformant with a chit42 gene from Trichoderma harzianum P1 and evaluation of its biocontrol activity against Botrytis cinerea. J. Microbiol. 2013, 51, 166-173. [PubMed]

16. Siti, N.A.; Nisa, R.M.; Lisdar, I.S. Potential of Chitinolytic Bacillus amyloliquefaciens SAHA 12.07 and Serratia marcescens KAHN 15.12 as Biocontrol Agents of Ganoderma boninense. Res. J. Microbiol. 2015, 10, 452-465.

17. Horikoshi, K.; Iida, S. Effect of lytic enzyme from Bacillus circulans and chitinase from Streptomyces sp. on Aspergillus oryzae. Nature 1959, 183, 186-187. [CrossRef] [PubMed]

18. David, B. From natural products to clinically useful antifungals. Biochim. Biophys. Acta 2002, 1587, $224-233$.

19. Chen, X.H.; Koumoutsi, A.; Scholz, R.; Junge, H. Comparative analysis of the complete genome sequence of the plant growth-promoting bacterium Bacillus amyloliquefaciens FZB42. Nat. Biotechnol. 2007, 25, 1007-1014. [CrossRef] [PubMed] 
20. Wang, S.L.; Shih, I.L.; Liang, T.W.; Wang, C.H. Purification and characterization of two antifungal chitinases extracellularly produced by Bacillus amyloliquefaciens V656 in a shrimp and crab shell powder medium. J. Agric. Food Chem. 2002, 50, 2241-2248. [CrossRef] [PubMed]

21. Shen, X.; Chen, Y.; Liu, T.; Hu, X.; Gu, Z. Development of a high-efficient transformation system of Bacillus pumilus strain DX01 to facilitate gene isolation via gfp-tagged insertional mutagenesis and visualize bacterial colonization of rice roots. Folia Microbiol. 2013, 58, 409-417. [CrossRef] [PubMed]

22. Li, L.; Steffens, J.C. Overexpression of polyphenol oxidase in transgenic tomato plants results in enhanced bacterial disease resistance. Planta 2002, 215, 239-247. [CrossRef] [PubMed]

23. Gong, C.; Liu, Y.; Liu, S.Y.; Cheng, M.Z.; Zhang, Y.; Wang, R.H.; Wang, A.X. Analysis of clonostachys rosea-induced resistance to grey mould disease and identification of the key proteins induced in tomato fruit. Postharvest Biol. Technol. 2017, 123, 83-93. [CrossRef]

24. Alamelumangai, M.; Dhanalakshmi, J.; Mathumitha, M.; Renganayaki, R.S.; Muthukumaran, P.; Rajalakshmi, N. Modulation of banana polyphenol oxidase (ppo) activity by naturally occurring bioactive compounds from plant extracts. Int. J. Pharma Sci. Res. 2015, 6, 152-155.

25. Lu, J.; Xue, H.; Pan, Y.; Kan, S.; Liu, M.; Nechitailo, G.S. Effect of spaceflight duration of subcellular morphologies and defense enzyme activities in earth-grown tomato seedlings propagated from space-flown seeds. Russ. J. Phys. Chem. B 2009, 3, 981-986. [CrossRef]

(C) 2018 by the authors. Licensee MDPI, Basel, Switzerland. This article is an open access article distributed under the terms and conditions of the Creative Commons Attribution (CC BY) license (http://creativecommons.org/licenses/by/4.0/). 